\title{
Using a Student-Generated Survey to Inform Planning For a User-focused Learning Commons
}

By Sharon A. Weiner and John M. Weiner

\begin{abstract}
\section{Introduction}

To support undergraduate learning at the University of Massachusetts Dartmouth, the Library planned a learning commons as part of an extensive renovation project. The planning process included a review of the education and library literature, site visits to existing commons, consultations with experts in the field, involvement of key campus stakeholders, and survey data. This article is a report of a pilot survey conducted to engage students in the planning process and identify their needs related to a learning commons from a student perspective. This survey was developed and administered with the assistance of undergraduate students in introductory statistics courses.
\end{abstract}

A master's comprehensive University is planning a learning commons to support undergraduate learning. The planning process included a literature review, site visits to commons, consultations with experts in the field, discussions with campus specialists, and surveys of patrons. The literature reports two primary forms of data gathering for learning commons: interview/observation and purposive surveys. This report describes the findings of a survey conducted to determine students' perceptions of services relevant in learning commons. The findings indicated that the students wanted help with their information processing needs.

\section{Why a Learning Commons?}

Institutions of higher education are changing their educational approach from a "teaching” paradigm to a "learning" paradigm. This transformation requires an emphasis on student learning outcomes; the inclusion of faculty as well as other campus professionals as partners in student learning; the seamless integration of technology in learning; and acknowledgement that learning occurs through all aspects of a student's college experience ${ }^{1}$. These changes in higher education as well as rapid advances in technology have prompted modifications to the structure, functions, and services offered by academic libraries ${ }^{2,3,4,5,6,7}$. The library has a significant role in the learning process, in fact, it "may be the most important observation post for studying how students really learn. If the core competency of the university is the capacity to build collaborative spaces, both real and intellectual, then the changing nature of the library may be a paradigm for the changing nature of the university itself”,

There is recognition that libraries should engage in ongoing self-evaluation to ensure that they provide sufficient support for learning modalities ${ }^{9,10,11,12}$. The academic library is a core resource for learning, and "the library staff should be considered as important to teaching as are classroom teachers"13. Faculty and librarians who work together on library-based learning can stimulate positive learning experiences for students. Some characteristics of a "good learning experience" are that: it helps to develop information literacy competency; it is customized to the student's immediate needs and learning style; and it occurs in a non-threatening environment ${ }^{14}$.

One innovative concept for space, services, and operations to support undergraduate learning developed during the last twenty years is the "learning," "information," or "knowledge commons." While the mix varies by site, a commons integrates traditional library services with other learning support services on a campus, such as information processing, tutorial services, report preparation, enhanced technology, and preparation of visual displays ${ }^{15,16,17,18,19}$. The design of an information commons facilitates interaction and serendipitous learning $^{20}$. A learning commons differs from an information commons because it focuses on the creation of knowledge over the transmission of knowledge $^{21}$. A learning commons is "clearly and explicitly aligned strategically with the institution-wide vision and mission - that is, is a dynamic and active partner in the broad educational enterprise of the institution, not just the library-centric enterprise" ${ }^{\text {22 }}$. Its parent library fosters a philosophy of integration with its campus. The technology resources are greater in a learning commons and are seamlessly integrated. The collaborative work spaces are many and varied. A learning commons is not library-centric; it is learnercentered. It incorporates related learning support functions within the library and reaches out to them outside of the library ${ }^{23}$.

The popularity and use of commons by students whenever they are implemented provides support for 
their importance. Published reports of success with the commons concept have focused on space design, staffing issues, and service models. The purpose of these reports was to provide insights that would aid in planning. Data capture to inform decision-making included surveys, focus groups, interviews, and site visits. "Best practice" is a frequently cited justification for the service configuration adopted. Changes in a library's operational strategy imply additional costs for facility renovation, changes in service configurations, changes in operational procedures, training of personnel for new roles, and the integration of differing functions. Definitive data can justify the expense and effort and motivate the acceptance of a new model.

\section{Description of University of Massachusetts Dartmouth Library}

The Claire T. Carney Library at the University of Massachusetts Dartmouth (UMD) is the focal point of a campus that serves a masters comprehensive institution with a student population of over 9,000 FTE's. At the time of the survey, the Library was engaged in a plan for a building renovation. The first floor of the Library was open with many windows and few book stacks or visual obstructions. There was some seating, but the area was primarily used for university functions such as lectures and banquets. The second floor included the reference desk and reference collection, along with 40 public workstations. The fourth floor included the Archives and Special Collections. Floors 3-5 were filled with book stacks along with some seating for individuals along the perimeter windows and banks of seating interspersed through the stacks. The lower level had been renovated to include two computer labs and the PhotoGraphic Services Department which provided photography, videography, and graphic design service to the campus. Offices for the Library staff and most of the Computing and Information Technology Services staff were located throughout the building. Other related services were located in other buildings. The campus Writing Center was located in the building for the College of Arts and Sciences. Tutoring services were located in respective academic subject areas.

Clearly, learning support services were dispersed throughout the campus and were not well-integrated or coordinated. This model worked well until changes in learning preferences and recent trends in higher education favored closer cross-departmental relationships and easier access to services by the student population. Initially, faculty and other learning specialists were interviewed to determine their suggestions and insights regarding the nature and function of the commons-in-planning. The purpose of this report was to describe a survey to determine student perceptions in relation to a proposed learning commons.

\section{The Student Perspective}

Since learning commons are student-centered, it is important to involve students in the planning process and to incorporate their perspective into the planning. In this project, several students were members of a campus-wide planning committee; and leaders of the learning commons project reported on it at Student Senate meetings. Another opportunity for student participation and feedback occurred when a professor assigned students in his introductory statistics classes to develop and administer a survey relating to student perspectives on learning commons-related services. Surveys are useful for obtaining information about physical and digital services for learning commons and can also provide information about the people needed to provide support services ${ }^{24 .}$

\section{Elements of Learning Support Services}

The literature indicates that traditional library services, tutoring, computer instruction, the study hall environment, and report preparation are important elements of learning support services for students. A well-planned learning commons integrates these elements in its design.

\section{Traditional Library Services}

Reference and other informational services are core to an academic library's operation ${ }^{25,26,27,28}$. Libraries have a role in teaching information management skills and information literacy competencies that can become a "comprehensive knowledge management paradigm"29. At the Claire T. Carney Library, there was a reference desk on the second floor while the circulation desk was on the first floor.

\section{Tutoring}

Tutoring services may be provided through individual appointments; walk-in, email, or telephone service; study groups; and online instruction. Students who use tutoring services can take a more active role in their own learning processes. Because there is a social dimension to tutoring services, more effective learning may occur. These services can have a positive influence on GPA, course passing rates, course completion rates, persistence, and retention rates ${ }^{30,31}$. Tutoring services at UMD were dispersed in the buildings of the College that supported them; there were no tutoring services in the library. 


\section{Computer Instruction}

Computer literacy is essential to the successful functioning and global competitiveness of our citizenry. "Citizens who do not posses these critical skills are far more likely to be unemployed and in poverty and are far less likely to be in professional, managerial, or technical positions" ${ }^{\text {,3 }}$. Instruction in the use of computer hardware and software at UMD occurred in campus computer labs managed by the information technology department or in computer labs managed by academic departments. While valuable, these learning opportunities were often independent of other learning capabilities. By integrating the various instructional and learning opportunities in the learning commons, a student would develop the skills and knowledge in presumably a more effective and lasting way. That hypothesis would be essential to study as the learning commons became a reality. However, this survey was designed to determine student perceptions prior to the development of integrated learning opportunities and facilities.

\section{Study Hall Environment}

Students need quiet spaces for individual study. This is particularly true of graduate students and faculty. Architectural designs for renovated or new library buildings include spaces conducive to quiet study. The study hall environment is an important learning and social area in libraries ${ }^{33,35,36,37,38,39,40}$. At UMD, the main floor of the library was often used for campus receptions and lectures. Quiet study occurred on the other floors of the library. Those were the locations for the book stacks and some staff offices. A frequent first step in creating a commons is an emphasis on facility renovation. This survey explored the importance placed on the environment by students.

\section{Preparation of Reports}

Including writing centers in academic libraries may be the optimal way to maximize relationships between departments, foster collaboration, and expedite referrals ${ }^{41}$. Librarians and writing center professionals work with highly integrated processes to help students to construct new knowledge ${ }^{42}$. "Writing centers and information literacy instruction have grown to a point where formal collaborative partnerships might be the best way to open new lines of development...more powerful, more dynamic, and more effective instructional practice can be achieved than either has been able to achieve alone" ${ }^{\text {a }}$. The location for the Writing Center at UMD was in the building for the College of Arts and Sciences.
This survey included four dimensions of possible learning commons services: tutoring, computer instruction, study hall, and report preparation. In libraries that do not have learning commons, tutoring services are usually restricted to instruction about library services and resources and assistance with library-supported database searches. A learning commons could also include tutoring in academic subject areas, writing, software use, and information utilization. This study also considered the study hall function.

\section{Methods}

The literature reports two primary forms of data gathering for learning commons:

interview/observation of best practices and purposive surveys of patrons ${ }^{44,45,46,47,48,49}$. A survey is a structured set of questions designed to elicit descriptions of characteristics representing feelings, attitudes, perceptions, or experiences ${ }^{50}$. Responses can be collected by capturing the verbal and/or written expressions provided by the respondent.

Students in two introductory statistics courses assisted in the development and administration of a preliminary survey questionnaire to 100 students at the University of Massachusetts Dartmouth. This was a convenience sample selected by the students in the course and was intended to serve as the data spring board for a larger more definitive survey of students and faculty. The intent of this questionnaire was to determine which items to incorporate into a larger study. The response rate was $58 \%$. SPSS was used to compute the statistical results.

\section{Results}

\section{Demographic Characteristics and Academic Majors}

The literature identified variables such as generational characteristics and student status as important demographic variables for studies of college students ${ }^{52}$. Considering those findings, the study included the following variables: age, residence, and work status. Most of the respondents (60\%) were in the age range from $18-20$ and most lived on campus (79\%). The majority of the respondents were sophomores (45\%) Most of the respondents declared majors in the Colleges of Arts \& Sciences or Business. The percentage of respondents by major was proportional to the percentage of the student population in each major. The ages of more than $60 \%$ of the respondents ranged from 18-20 and about 30\% ranged from 21-23. First-year students represented $12 \%$ of the respondents; sophomores represented $45 \%$; juniors were $17 \%$ of the total; and seniors were $26 \%$. Seventy-one percent of 
the respondents indicated that their grade point average was at least "B."

\section{Study Hall Environment}

The questions dealing with this environment probed to understand the students' impressions regarding the adequacy of the present library environment for study purposes. The study hall questions included items regarding conference rooms, computer workstations, and spaces for individual or small group study. The responses to the questions were organized to capture intensity of feeling regarding the adequacy of each item. Most of the students found the present study environment in the library, the computer software available, the computer-supported instructional material resources, and the lounging areas to be acceptable. However, fewer than half were satisfied with the group conference rooms and number of computer workstations.

\section{Tutorial Services}

The questions relating to tutorial service were addressed. The questions were:

- Knowledge of present tutorial services

- Quality of tutorial services provided in the library

- Tutoring services desired by the respondent

- Sources of present tutoring services

- Access to tutoring programs

- Perceived need for tutorial services

Fewer than half of the respondents knew about any of the tutoring services. Only about one-third commented that the quality of the services offered in the library was average; another one-third did not comment. Approximately one-third of the students indicated that they would like to use literature search, mathematics/statistics, science subjects, and report preparation services. A little more than one-third of the respondents indicated that they had minimal need for tutorial services.

\section{Relationship between Study Fall Environment and Tutorial Services}

The possibility of a relationship between the study hall and tutorial services dimensions was explored by stepwise linear regression ${ }^{53}$ using a combination of the study hall questions as the dependent variable and the responses to the six tutorial services questions as independent predictors. This process is helpful in finding variables likely to be important in subsequent analyses. Principal Components of Variance ${ }^{54}$ was used to construct the study hall combination variable.
At each step in the stepwise regression process, the independent variable selected had the highest partial correlation with the dependent variable and contributed significantly to the regression. The regression explained about $32 \%$ of the variation in the study hall variable $(p<0.05)$. Three variables from the tutorial set were statistically significant. Those variables were: desire to use a humanities tutorial service; desire to use a display preparation tutorial service; and a question dealing with access to existing tutorial programs.

Display preparation is a skill that is easily recognized as valuable in enhancing student generated reports. The need for a humanities tutorial service may indicate a deficiency that was of concern to the respondents. Access to tutorial services should be easy. Instead, only $12 \%$ of the respondents considered that the tutorial services were easily accessible.

\section{Report Preparation Services}

Four questions probed for students' impressions of existing and desired report preparation services. The first involved identifying the tasks found to be difficult to accomplish. From one-quarter to one-third of the respondents had difficulty in finding literature, editing and revising, organizing notes and data, preparing drafts, developing a bibliography, or developing an outline for a report. The second question dealt with sources in finding literature. Forty-eight percent indicated that internet search engines were most useful while thirty-one percent indicated that reference librarians were most useful. The third question considered editing and revising drafts. The students reported that classmates and teachers were most useful. The fourth question dealt with the most useful source in developing the bibliography. The predominant response was internet search engines. None of these variables were related to study hall environment.

\section{Instruction in Computer Software}

This dimension had three questions. The first dealt with identifying the software that the respondents found difficult to use. Statistical software (36\%) and business software (38\%) were most frequently cited. Sources of assistance recognized were friends and computer facility staff. When asked to indicate preferred instructional modes desired in learning software, the respondents chose web instruction.

\section{Predicting Study Hall Environment}

A stepwise regression was performed to identify the variables that were likely to be relevant in enhancing the study hall environment. All of the variables from the tutorial services, report preparation, computer 
operation, and personal/demographic dimensions were included in the analysis. The stepwise procedure identified the following variables as statistically significant:

- Access to existing tutorial programs

- Special tutorial programs on campus

- Display preparation tutorial

- Difficulty preparing displays

These four variables explained about $38 \%$ of the variation in the measure of study hall environment. Omitted from the relationship were variables from the computer software operation and personal/demographic dimensions. Interestingly, two of the variables selected as relevant had to do with display assistance. The other two variables dealt with access to and availability of tutorial services.

\section{Subgroup Analyses}

The possibility that different subgroups of the students might require different kinds of services was explored using class standing, age, grade point average, and major area of study. For each subgroup, the relationship between the study hall environment variable and the tutorial services, report preparation, and computer operation dimensions was analyzed using stepwise regression.

\section{Age 18-20}

Thirty-six (64\%) of the respondents were in this subgroup. The study hall environment factor was related to three variables, all from the tutorial services dimension. The first variable was the student's awareness of accessibility to existing tutorial services. Awareness of special tutorial programs on campus was second and the students' desire to use a humanities tutorial service was third.

\section{Age 21-23}

Sixteen respondents (29\%) were in this subgroup. The regression involved one variable, the student's perception of access to existing tutoring programs.

\section{Grade B or Better}

Forty respondents (69\%) were in this subgroup. The regression involved four variables. The first was the student's perceived access to existing tutorial programs. Identification of the best source in developing a bibliography was the second selected. The remaining two dealt with the student's knowledge of tutorial services - research design and science subjects.

\section{Business Majors}

Fifteen students (26\%) were in this subgroup and two variables were entered into the regression. The first was the source for developing a bibliography. The second was the student's awareness of departmental tutorial services.

\section{Discussion}

The intent of this survey was to expand on the frequently reported practices for planning learning commons by including a preliminary survey of student perceptions of their learning needs and how the library can assist in accomplishing them. The findings were intended to identify the questions to be used in a larger survey of students and faculty. However, Some of the findings were unexpected. The emphasis on tutorial service requirements suggested that the planning emphasize specific services instead of the usual first focus on environmental changes.

The student respondents were predominantly sophomores (45\%) and seniors (26\%). The majority were from the ages of 18-20 (64\%) followed by ages 21-23 (29\%). Seventy-nine percent lived on campus and $94 \%$ were full-time students. Seventy-one percent had a grade point average of $\mathrm{B}$ or better. The respondents to this survey formed a 'reasonable representation' because the percentages of students within major educational programs were close to the ones cited for those particular programs.

Assuming that the respondents do represent the student body of interest, the environment needed to provide the 'ideal' learning commons, based on literature reports and expert opinions, would include programs designed to assist the student in furthering his/her learning outside of the classroom.

What services provide that capability and who should sponsor them? The results indicated that two issues were relevant to the responding students. One was the tutorial service including a range of subjects and accessibility. This is a form of on-demand learning in which the student recognizes a learning obstacle and seeks assistance in resolving it. Respondents indicated difficulty in finding literature, editing and revising, organizing notes and data, preparing drafts, developing a bibliography, developing an outline, and putting the package together. Their sources of assistance also were clues to the need for a more comprehensive tutorial process. They received editing and revising assistance from classmates. They used internet search engines to build bibliographies. The students favored web instruction for software. That mode of instruction 
could be useful in other subjects as well. "In recent years, there has been a transition in library instruction from a tool-based approach to a problem-solving and learning approach, which necessitates working closely with the writing center" ${ }^{\text {, }}$.

The results of this survey underscore the importance of the learning commons in supplementing the instructional effort. The classroom is a recognized site for dissemination of information and stimulation of critical thinking. A conservative recommendation suggested that the student study three hours a week for every hour spent in class ${ }^{58}$. The learning commons concept gives the student a place to accomplish this recommendation together with the necessary assistance to make the time fruitful.

While the study recommendation may be based on sound experience, another consideration is evident. Students exhibited a desire for rapid acquisition and processing of information. This desire can be addressed with a learning commons. The tutorial services that seem to be relevant are those that provide the student with an immediate response to a learning need. Computer-supported text mining, organization of information, and analysis can enhance productivity. Those services call for integration of computer, library, and instructional technologies to form the supplements appropriate in this on-demand learning environment. If the students in this survey are representative of the population of students in colleges today, the emphasis on library-based programs may take precedence over physical changes to the facility.

These results can inform other academic libraries interested in developing surveys to garner student feedback about learning commons. Potentially important areas for further probing include the following:

- Need for tutorial services

- Need for trained peer consultants

- Use of internet resources for information access

- Use of internet for bibliographic development

Students indicated a repeated need for tutorial services and assistance with processing information. These included: finding literature, editing and revising, organizing notes and data, preparing drafts, developing a bibliography, developing an outline, and putting the package together. The finding that students preferred to obtain assistance from peers supports the possibility of introducing trained, peer consultants to provide a primary level of assistance in answering student queries. The increasing use of internet resources as well as the increasing concern regarding the 'value' of such sources suggests more emphasis on this area in future surveys. Similarly, the findings suggest that students' perceptions regarding ways of providing instruction in effective information use should be emphasized.

\section{Conclusion}

This survey captured data at one university regarding students' attitudes, needs, and perceptions regarding a set of services to enhance undergraduate learning. The logical site for the innovative services is the academic library. This resource is called by various names including "learning," "information,” or "knowledge commons.” Planning was accomplished by reviewing the education and library literature, site visits to existing commons, consultations with experts in the field, discussions with campus stakeholders, and surveys of patrons. The literature reports two major forms of data gathering: interview/observation of best practices and purposive surveys of patrons.

The inclusion of a variable for a study hall environment was based on the obvious importance placed on appearance and comfort. Remodeling a library may take precedence over restructuring programs. Acquiring furniture may take precedence over instruction occurring in the library. The results of the relationship analysis suggested that a study hall environment wasn't necessarily a priority for the students in a public university with a student body consisting of undergraduate and masters programs. Seventy-six percent found the present environment (i.e., before remodeling) acceptable. Forty-eight percent felt that there were sufficient computers and fifty-eight percent considered the software to be adequate. Sixty-one percent felt that lounging areas were satisfactory. These results confirm the lower priority placed on the environment by the students.

Subgroup analysis showed the apparent importance of tutorial services and the need for instruction in information processing. The classroom is the recognized site for the dissemination of new knowledge and the stimulation of critical thinking. However, without supplemental assistance in acquiring the necessary skills, the time to achievement may be long and the frustrations high. Those observations and the desire to provide solutions have motivated many academic libraries to include a learning commons. That environment may differ in services and structure 
in each university. However, all are intended to enhance learning.

There is evidence to indicate that students are knowledgeable about computers but may not have information literacy competencies. This survey reinforces that evidence. The students clearly identified the need for tutorial services related to information processing and emphasized the desirability that these be easily accessible. That desire matches another involving more rapid and specific learning of required material. These findings suggest additional areas to probe with students in developing a datadriven plan for a learning commons.

\section{Appendix I. Survey Instrument.}

\section{Survey of Library Services}

Libraries are in a transition from the services and beliefs associated with the traditional repository of knowledge to one of active involvement in learning. However, in making this transition, there are differing opinions regarding the array of the new library services and functions. In addition, differing approaches in providing services have been suggested. To assist the staff at the Claire T. Carney Library at the University of Massachusetts Dartmouth develop the innovative, effective program of services you require, please take a few minutes to answer this important survey. This survey will be kept confidential. Please sign below to indicate that you have read this consent form and agree to fill out the survey."

Should the library provide a study hall environment? Libraries have introduced various areas intended to enhance study opportunities including conference rooms, computer stations, educational carrels, and quiet rooms. Studies have suggested that students prefer two types of areas - quiet and social - both considered as examples of an ideal study environment.

Please answer the following questions regarding the Library's present study environment. Respond by circling the answer or answers that best describe your experience and needs.

1.

2.

3.

4.
5. Do the computers provide the necessary software?

Present study environment is ---?

a. Poor

b. Acceptable

c. Outstanding

d. Unknown, don't use library

Present individual study space is ---?
a. Very inadequate
b. Below average
c. Acceptable
d. Above average
e. Very adequate
f. Unknown

Present conference rooms for small group study are ---?
a. Very inadequate
b. Below average
c. Acceptable
d. Above average
e. Very adequate
f. Unknown

The number of existing computer stations are ---?
a. Too few
b. Sufficient
c. More than needed
d. Unknown

a. In less than $25 \%$ of the computer stations throughout the library 
b. In about $50 \%$ of the computer stations throughout the library

c. In all of the computer stations throughout the library

d. Unknown

6. The number of educational carrels are ---?
a. Too few
b. Adequate
c. Sufficient
d. Unknown

7. The technology supported by the educational carrels is --- ?
a. Outdated
b. Reasonably current
c. State of the Art
d. Unknown

8.

The library's computer-supported instructional material resources are ---?
a. Very inadequate
b. Below average
c. Acceptable
d. Above average
e. Very adequate
f. Unknown

9. The availability of lounging areas is ---?
a. Very inadequate
b. Below average
c. Acceptable
d. Above average
e. Very adequate
f. Unknown

Should the Library provide Tutoring Services? As libraries change to meet current needs, there has been emphasis on providing facilities and services that supplement learning opportunities offered in the classroom. One such supplement might be tutorial services.

1. $\quad$ Present tutoring services include - (circle all that you know about)?
a. Search strategies for literature
b. Bibliographic Instruction
c. Computer Operation
d. Science subjects
e. Mathematics/Statistics
f. Professional Studies
g. Humanities
h. Research Design
i. Text Analysis
j. Report Preparation
k. Display Preparation

2. Quality of present tutorial services provided in the library are ---?
a. Poor
b. Below Average
c. Average
d. Above Average
e. Outstanding
f. Unknown

3. What tutoring services would you like to use - (circle all of interest)?

a. Search strategies for literature

b. Bibliographic Instruction 

c. Computer Operations
d. Science subjects
e. Mathematics/Statistics
f. Professional Studies
g. Humanities
h. Research Design
i. Text Analysis
j. Report Preparation
k. Display Preparation

4. Sources of tutoring services presently available - (circle all you have used)?
a. Departmental
b. Special Programs on campus
c. For-Hire tutors

5.

Access to existing tutoring programs?
a. Poor
b. Difficult
c. Acceptable
d. Easy
e. Very Easy
f. Unknown

6. Your perceived need for tutorial services?
a. Minimal
b. Average
c. Moderate
d. Urgent

Should the library include report preparation services? Libraries have been the repositories for knowledge. As they change to active learning centers, the utilization of information and its dissemination become more important.

1.

Which tasks do you have difficulty in accomplishing - (circle all that apply)?

a. Finding literature on the subject

b. Organizing notes and data from the literature

c. Developing an outline for the report

d. Preparing drafts of the report

e. Editing and revising

f. Developing the bibliography

g. Preparing displays

h. Developing a completed package

2. Which source was most useful in finding literature for a report?
a. Reference librarians
b. Internet search engines
c. Special Programs on Campus
d. Classmates
e. Friends
f. Family
g. Teachers

3. Which source was most useful in editing and revising drafts?
a. Reference librarians
b. Internet search engines
c. Special Programs on Campus
d. Classmates
e. Friends
f. Family
g. Teachers 
4. Which source was most useful in developing a bibliography for your report?
a. Reference librarians
b. Internet search engines
c. Special Programs on Campus
d. Classmates
e. Friends
f. Family
g. Teachers

Should the library include computer software operation services? Computers are an important tool in identifying, organizing, analyzing and disseminating information. Should the library actively feature this technology as part of its array of new active learning center services?

1. Indicate the software that you have difficulty using (circle all that apply)?
a. E mail
b. Internet
c. Word Processing
d. Statistical software
e. Spreadsheets
f. Search engines
g. Literature sources
h. Presentation software
i. Business/Accounting software
j. Text Analysis software

2. Which source was most useful in offering help in using software?
a. Librarians
b. CTIS staff
c. Special Programs on Campus
d. Classmates
e. Friends
f. Family
g. Teachers

3. What form of instruction would you consider most desirable in learning software?
a. Via email
b. Via web instruction
c. Via Special Programs on Campus
d. From Classmates
e. From Friends
f. From Family
g. None

Special Characteristics? The following questions are intended to identify your group attributes. This information is important in ensuring that space and facilities are allocated commensurate with important individual and group needs.

1. What is your class standing?

b. Freshman

c. Sophomore

d. Junior

e. Senior

2. How old are you?
a. Less than 18
b. $18-20$
c. $21-23$
d. $24-26$ 
e. $26-28$

f. 29 or older

3. Where do you live?

a. On campus

b. Off campus

4. What is your grade point average?

a. B or better

b. Less

5. What is your area of interest?

a. Arts \& Sciences

b. Business

c. Engineering

d. Nursing

e. Visual \& Performing Arts

f. Marine Science

g. Continuing Education

h. Other

6.

What times would be most convenient for you to use the library? (circle all that apply)

a. Between 8:00 AM and 5:00 PM

b. Between 5:00 PM and Midnight

c. Between Midnight and 8:00 AM

7. What days would be most convenient for you to use the library? (circle all that apply)

a. Monday

b. Tuesday

c. Wednesday

d. Thursday

e. Friday

f. Saturday

g. Sunday

8. What is your current work status?

a. Full-time student

b. Student \& Part-time work

c. Student \& Full-time work

By answering these questions carefully, you are helping in the design of the first, data-driven, student-centered learning commons in the world. It will happen at the University of Massachusetts Dartmouth because of you. Thank you for participating in this survey. 


\section{References}

${ }^{1}$ Guskin, Alan E. and Mary B. Marcy. "Dealing with the Future Now: Principles of Creating a Vital Campus in a Climate of Restricted Resources.” Change 35, no. 4 (2003): 13-14.

${ }^{2}$ Bailey, D. Russell and Barbara Gunter Tierney, Transforming Library Service through Information Commons: Case Studies for the Digital Age (Chicago: American Library Association, 2008), 6-7.

${ }^{3}$ Bracke, Marianne Stowell, Michael Brewer, Robyn Huff-Eibl, Daniel R. Lee, Robert Mitchell, and Michael Ray. "Finding Information in a New Landscape: Developing New Service and Staffing Models for Mediated Information Services.” College \& Research Libraries 68, no. 3 (2007): 248-67.

${ }^{4}$ Church, Jennifer. "The Evolving Information Commons.” Library Hi Tech 23, no. 1 (2005): 75-81.

${ }^{5}$ Cowgill, Allison, Joan Beam, and Lindsey Wess. "Implementing an Information Commons in a University Library.” The Journal of Academic Librarianship 27, no. 6 (2001): 432-9.

${ }^{6}$ MacWhinnie, Laurie A. "The Information Commons: The Academic Library of the Future.” portal: Libraries and the Academy 3, no. 2 (2003): 241-57.

${ }^{7}$ Spencer, Mary Ellen. "Evolving a New Model: The Information Commons.” Reference Services Review 34, no. 2 (2006): 242-7.

${ }^{8}$ Duderstadt, James J. "Possible Futures for the Research Library in the 21st Century.” Journal of Library Administration 49, no. 3 (2009): 220.

${ }^{9}$ Ritchie, Lorin and Kathlin Ray. "Incorporating Information Literacy into the Building Plan: The American University of Sharjah Experience.” Reference Services Review 36, no. 2 (2008): 167-79.

${ }^{10}$ Shill, Harold B. and Shawn Tonner. "Creating a Better Place: Physical Improvements in Academic Libraries, 1995-2002.” College \& Research Libraries 64, no. 6 (2003): 431-66.

${ }^{11}$ Shill, Harold B. and Shawn Tonner. "Does the Building Still Matter? Usage Patterns in New, Expanded, and Renovated Libraries, 19952002.” College \& Research Libraries 65, no. 2 (2004): 123-50.

${ }^{12}$ Whitchurch, Michael J., C. Jeffrey Belliston, and William Baer. "Information Commons at Brigham Young University: Past, Present, and
Future.” Reference Services Review 34, no. 2 (2006): 261-78.

${ }^{13}$ Boyer, Ernest L., College: The Undergraduate Experience in America, (New York: Harper \& Row, 1987), 164.

${ }^{14}$ Breivik, Patricia Senn and E. Gordon Gee, Information Literacy: Revolution in the Library. (New York and London: American Council on Education/Macmillan Publishing Company, 1989), 38-9.

${ }^{15}$ Bailey and Tierney. Transforming Library Service.

${ }^{16}$ Bracke, Brewer, and Huff-Eibl. "Finding information," 248-67.

${ }^{17}$ Franks, Jeffrey A. "Introducing Learning Commons Functionality into a Traditional Reference Setting.” E-JASL: The Electronic Journal of Academic \& Special Librarianship 9, no. 2 (2008).

${ }^{18}$ Mahaffy, Mardi. "Exploring Common Ground: US Writing Center/Library Collaboration.” New Library World 109, no. 3/4 (2008): 173-81.

${ }^{19}$ Spencer. "Evolving a new model," 242-7.

${ }^{20}$ Beagle, Donald Robert, The Information Commons Handbook. (New York and London: NealSchuman Publishers, Inc., 2006), xvii.

${ }^{21}$ Bailey and Tierney. Transforming Library Service, 2. ${ }^{22}$ Ibid. 3,

${ }^{23}$ Ibid. 3,

${ }^{24}$ Beagle, Information Commons Handbook, 67.

${ }^{25}$ Crockett, C., S. McDaniel, and M. Remy. "Integrating Services in the Information Commons: Toward a Holistic Library and Computing Environment.” Library Administration \& Management 16, no. 4 (2002): 181-6.

${ }^{26}$ Fitzpatrick, EB, AC Moore, and BW Lang. "Reference Librarians at the Reference Desk in a Learning Commons: A Mixed Methods Evaluation.” Journal of Academic Librarianship 34, no. 3 (2008): 231-8.

${ }^{27}$ Gardner, Susan. "Tiered Reference: The New Landscape of the Frontlines.” Electronic Journal of Academic \& Special Librarianship 7, no. 3 (2006).

${ }^{28}$ Case, Mary M. "Partners in Knowledge Creation: An Expanded Role for Research Libraries in the Digital Future.” Journal of Library Administration 48, no. 2 (2008): 141-56.

${ }^{29}$ Euster, Joanne R., "The Academic Library: Its Place and Role in the Institution," In Academic Libraries: Their Rationale and Role in American Higher Education, G. B. McCabe 
and R. J. Person, eds., (Westport, CT: Greenwood Press, 1995), 7.

${ }^{30}$ Hendriksen, Sharon Ishiki, Lifen Yang, Barbara Love, and Mary C. Hall. “Assessing Academic Support: The Effects of Tutoring on Student Learning Outcomes.” Journal of College Reading and Learning 35, no. 2 (2005): 61.

${ }^{31} \mathrm{Xu}$, Yonghong, Stacey Hartman, Guillermo Uribe, and Reed Mencke. "The Effects of Peer Tutoring on Undergraduate Students' Final Examination Scores in Mathematics.” Journal of College Reading and Learning 32, no. 1 (2001): 30-31.

${ }^{32}$ Tyson, John C., "The Impact of Emerging Technologies on Library Clientele," in The Impact of Emerging Technologies on Reference Service and Bibliographic Instruction, G. M. Pitkin, ed., (Westport, CT: Greenwood Press, 1995), 65-6.

${ }^{33}$ Dewey, BI. “Social, Intellectual, and Cultural Spaces: Creating Compelling Library Environments for the Digital Age.” Journal of Library Administration 48, no. 1 (2008): 85-94.

${ }^{34}$ Ritchie and Ray. 2008. "Incorporating Information Literacy,” 167-79.

${ }^{35}$ Shill and Tonner. 2003. "Creating a Better Place," 431-66.

${ }^{36}$ Shill and Tonner. 2004. "Does the Building still Matter?” 123-50.

${ }^{37}$ Weber, MA, and RK Flatley. "What Do Students Want? A Focus Group Study of Students at a Mid-Sized Public University.” Library Philosophy \& Practice 10, no. 1 (2008): 1-11.

${ }^{38}$ Gorham, Lane. “Assessing the Undergraduates' Use of the University Library.” College \& Research Libraries 27, no. 4 (1966): 277-82.

${ }^{39}$ Gardner, S., and S. Eng. "What Students Want: Generation $\mathrm{Y}$ and the Changing Function of the Academic Library.” portal: Libraries and the Academy 5, no. 3 (2005): 405-20.

${ }^{40}$ Mahaffy. "Exploring Common Ground,” 179.

${ }^{41}$ Hook, Sheril, "Teaching Librarians and Writing Center Professionals in Collaboration: Complementary Practices," in Centers for Learning: Writing Centers and Libraries in Collaboration, J. K. Elmborg and S. Hook, eds., (Chicago: Association of College and Research Libraries, 2005), 24.

${ }^{42}$ Elmborg, James K., and Sheril Hook, Centers for Learning: Writing Centers and Libraries. (Chicago: Association of College and Research Libraries, 2005).

${ }^{43}$ Beagle, The Information Commons Handbook, 1.

${ }^{44}$ Gardner and Eng. "What Students Want." 405-20.
${ }^{45}$ Schmidt, N., and J. Kaufman. "Learning Commons: Bridging the Academic and Student Affairs Divide to Enhance Learning Across Campus.” Research Strategies 20, no. 4 (2005): 242-56.

${ }^{46}$ Sherman, Stephen C. A User-centered Evaluation of the North Carolina State University Libraries Learning Common. A Master's Paper for the MS in LS degree, University of North Carolina at Chapel Hill, 2008.

${ }^{47}$ Spencer. "Evolving a New Model," 242-7.

${ }^{48}$ Weber and Flatley. "What Do Students Want?" 1-11.

${ }^{49}$ Ornstein, MD. "Survey Research.” Current Sociology 46, no. 4 (1998): iii-136.

${ }^{50}$ Bailey and Tierney. Transforming Library Service.

${ }^{51}$ Kuh, George D. 2009. The National Survey of Student Engagement: Conceptual Framework and Overview of Psychometric Properties [cited May 5 2009]. Available from http://nsse.iub.edu/2004_annual_report/pdf/20 04_Conceptual_Framework.pdf.

${ }^{52}$ Weisberg, Sanford, Applied Linear Regression, 3rd ed. (Hoboken, NJ: Wiley Interscience, 2005).

${ }^{53}$ Jolliffe, I. Principal Component Analysis, 2nd ed. (New York: Springer Verlag, 2002).

${ }^{54}$ Draper, Norman R. and Harry Smith, Applied Regression Analysis. (New York: Wiley, 1981).

${ }^{55}$ Fitzpatrick, Moore, and Lang. "Reference Librarians at the Reference Desk," 231-8.

${ }^{56}$ Hook, Sheril, “Teaching Librarians and Writing Center Professionals in Collaboration: Complementary Practices," in Centers for Learning: Writing Centers and Libraries in Collaboration, J. K. Elmborg and S. Hook, eds. (Chicago: Association of College and Research Libraries, 2005).

${ }^{57}$ Study Hour Formula 2009. Depaul A.C.E. Actively Choosing Education [cited May 5 2009]. Available from http://commerce.depaul.edu/undergrad/docs/A bout/studyhourformula.pdf. 
Acknowledgements: The authors wish to express their appreciation to the students of selected Introduction to Statistics classes at the University of Massachusetts Dartmouth for their participation in developing and conducting this survey. Also, the authors appreciate the diligent reporting of attitudes, perceptions and impressions by the students who took the survey.

Sharon A. Weiner, EdD

Professor and W. Wayne Booker Endowed Chair in Information Literacy

Purdue University Libraries

504 West State Street

West Lafayette, IN 47907-2058

sweiner@purdue.edu

(765) 496-3128 (phone)

John M. Weiner, Dr.P.H.

Adjunct Professor, College of Arts and Sciences

University of Massachusetts Dartmouth

285 Old Westport Road

North Dartmouth, MA 02747

weiner.john@tutorghost.com

615-504-9286 (phone) 